\title{
Effect of Limestone Powder on Hydration of $\mathrm{C}_{3} \mathrm{~A}-\mathrm{CaSO}_{4} \cdot 2 \mathrm{H}_{2} \mathrm{O}$ System
}

\author{
Jong-Kyu Lee ${ }^{\dagger}$, Yong-Sik Chu, and Hun Song \\ Green Ceramics Division, Korea Institute of Ceramic Engineering \& Technology, Seoul 153-801, Korea \\ (Received October 7, 2011; Revised October 26, 2011; Accepted November 25, 2011)
}

\section{$\mathrm{C}_{3} \mathrm{~A}-\mathrm{CaSO}_{4} \cdot 2 \mathrm{H}_{2} \mathrm{O}$ 계의 수화반응에 미치는 석회석 미분말의 영향}

\author{
이종규 ${ }^{\dagger}$ 추용식 · 송 훈 \\ 한국세라믹기술원 그린세라믹본부
}

(2011년 10월 7일 접수 ; 2011년 10월 26일 수정 ; 2011년 11월 25일 채택)

\begin{abstract}
In this work, effects of limestone powder on hydration of $\mathrm{C}_{3} \mathrm{~A}-\mathrm{CaSO}_{4} \cdot 2 \mathrm{H}_{2} \mathrm{O}$ system was discussed based on the XRD Quantitative analysis, and the possibility of Delayed Ettringite Formation was also discussed. The early hydration of $\mathrm{C}_{3} \mathrm{~A}$ was delayed by addition of $\mathrm{CaCO}_{3}$ powder. The delay effect was enhanced by increasing of $\mathrm{CaCO}_{3}$ content and finer powder of $\mathrm{CaCO}_{3}$ addition. After consumption of $\mathrm{CaSO}_{4} \cdot 2 \mathrm{H}_{2} \mathrm{O}$, the reaction of $\mathrm{CaCO}_{3}$ is started. Delayed Ettringite Formation would take place because monosulfoaluminate is not stable in presence of $\mathrm{CaCO}_{3}$. In order to prevent the delayed ettringite formation in $\mathrm{C}_{3} \mathrm{~A}-\mathrm{CaSO}_{4} \cdot 2 \mathrm{H}_{2} \mathrm{O}-$ $\mathrm{CaCO}_{3}$ system, the reduction of monosulfoaluminate formation is important. Therefore, by increasing the amount of $\mathrm{CaCO}_{3}$ addition and finer $\mathrm{CaCO}_{3}$ powder addition, the delayed ettringite formation can be prevented.
\end{abstract}

Key words : Limestone powder, Initial hydration, Monocarboaluminate, Delayed ettringite formation

\section{1. 서 론}

건설기술의 고도화, 다양화에 대응하고, 지구환경을 고 려한 건설재료의 순환시스템 확립을 위해 시멘트· 콘크리 트 재료 화학의 기초적인 연구가 더욱 중요해 지고 있다. 석회석은 시멘트·콘크리트의 재료로서 시멘트의 원료로서 이용되어지고 있고, 완전리사이클을 위한 콘크리트용의 세·조골재 등으로 사용하려는 움직임이 일고 있다. 또한 석회석을 분쇄한 미분말의 경우 고강도·고유동 콘크리 트용의 혼화재로 일본 등 에서는 이미 활용되어지고 있다. 최근 국내에서는 저품위의 석회석 미분말을 시멘트에 다량 혼합하는 혼합시멘트로 활용하고자 하는 움직임이 일고 있 다. ${ }^{1-3)}$ 이와 같은 석회석 미분말의 이용은 원가절감 차원 에서도 시멘트산업에서 매우 중요하며, 특히 에너지절감 및 시멘트 산업에서 이산화탄소 감축목표를 달성하기 위한 목적으로도 더욱 중요한 재료가 될 것이다.

석회석 미분말은 일반적으로 시멘트와 반응을 하지 않는 비활성 물질로 여겨지고 있지만 실제로는 시멘트 광물중 가 장 활성이 높고 초기 수화반응에 큰 영향을 미치는 $\mathrm{C}_{3} \mathrm{~A}$ 와

${ }^{\dagger}$ Corresponding author : Jong-Kyu Lee

E-mail : 1jk25@kicet.re.kr

Tel : +82-2-3282-2422 Fax : +82-2-3282-2430
반응을 하여 monocarbonate를 생성한다는 것과 $\mathrm{C}_{3} \mathrm{~S}$ 의 수 화반응을 촉진시킨다는 보고가 되어 있지만, $\mathrm{C}_{3} \mathrm{~A}$ 와 $\mathrm{CaCO}_{3}$ 의 수화반응에 대해서는 정량적인 관점에서의 상조성의 변화 등을 밝힌 연구는 아직 없다. ${ }^{4-8)}$

따라서 본 연구에서는 석회석미분말과 $\mathrm{C}_{3} \mathrm{~A}$ 와의 수화반 응성을 정량적으로 검토하기 위하여 실험실적으로 제조한 $\mathrm{C}_{3} \mathrm{~A}$ 와 $\mathrm{CaSO}_{4} \cdot 2 \mathrm{H}_{2} \mathrm{O}$ 의 일정 조성에 $\mathrm{CaCO}_{3}$ 를 첨가하여 $\mathrm{XRD}$ 정량분석을 실시하여 수화거동을 분석하였다.

\section{2. 실험방법}

\section{1. 시료}

$\mathrm{C}_{3} \mathrm{~A}$ 는 시약의 $\mathrm{CaCO}_{3}$ 와 $\mathrm{Al}_{2} \mathrm{O}_{3}$ 를 소정의 비율로 혼합하 고, 전기로에서 $1350^{\circ} \mathrm{C}, 3$ 시간 소성을 2 회 반복하여 합성 하였다. XRD에 의해 순수한 $\mathrm{C}_{3} \mathrm{~A}\left(\mathrm{BET}\right.$ 표면적 $: 0.48 \mathrm{~m}^{2} / \mathrm{g}$ )임 을 확인하였다. 석고는 BET 비표면적 $0.40 \mathrm{~m}^{2} / \mathrm{g}$ 의 분말도를 가지는 $\mathrm{CaSO}_{4} \cdot 2 \mathrm{H}_{2} \mathrm{O}$ 를 사용하였다. 석회석미분말(이하. $\mathrm{CaCO}_{3}$ 로 표기)의 비표면적영향을 분석하기 위해서 각각 $0.75 \mathrm{~m}^{2} / \mathrm{g}$ 과 $1.70 \mathrm{~m}^{2} / \mathrm{g}$ 을 사용하였다. 또한 $\mathrm{CaCO}_{3}$ 는 석회석을 분쇄한 것으로 $\mathrm{XRD}$ 에 의해 전부 calcite임을 확인하였다. 


\section{2. 수화시료의 준비}

$\mathrm{C}_{3} \mathrm{~A}-\mathrm{CaSO}_{4} \cdot 2 \mathrm{H}_{2} \mathrm{O}-\mathrm{CaCO}_{3}$ 계에서 $\mathrm{CaSO}_{4} \cdot 2 \mathrm{H}_{2} \mathrm{O}$ 의 첨가율은 $\mathrm{OPC}$ 에서의 $\mathrm{C}_{3} \mathrm{~A}$ 와 석고의 비를 감안하여 $\mathrm{C}_{3} \mathrm{~A}$ 1몰에 대해서 $\mathrm{CaSO}_{4} \cdot 2 \mathrm{H}_{2} \mathrm{O} 2 / 3$ 몰을 기본으로 하였다. $\mathrm{CaCO}_{3}$ 의 첨가량은 $\mathrm{C}_{3} \mathrm{~A}-2 / 3 \mathrm{CaSO}_{4} \cdot 2 \mathrm{H}_{2} \mathrm{O}$ 에 대해서 비표면적 $0.75 \mathrm{~m}^{2} / \mathrm{g}$ 을 가지는 것을 중량비로 $15 \%, 30 \%$ (내할)첨가를 하였다. 또한 분말 도의 영향을 살펴보기 위하여 비표면적 $1.70 \mathrm{~m}^{2} / \mathrm{g}$ 의 것을 $15 \%$ 첨가하였다. 그리고 $\mathrm{CaSO}_{4} \cdot 2 \mathrm{H}_{2} \mathrm{O}$ 첨가량에 따른 영 향을 검토하기 위하여 $\mathrm{C}_{3} \mathrm{~A}$ 에 대해서 $1 / 3,2 / 3,1$ 몰을 첨 가하여 비교분석을 하였다.

위의 각 조성을 소정의 비율로 혼합한 시료를 물/분체 비 $=0.6,20^{\circ} \mathrm{C}$ 에서 양생을 하였다.

\subsection{XRD에 의한 상조성의 결정}

수화물의 합성과 정량방법에 대한 논문을 참고하여 다 음과 같이 반응율 및 수화생성물의 정량분석을 실시하였 다. ${ }^{9,10)} \mathrm{C}_{3} \mathrm{~A}$ (정량 대상에 대한 측정범위 및 면지수, $2 \theta: 32.7$ $\left.33.7^{\circ}, \mathrm{d}: 2.69 \AA\right), \mathrm{CaSO}_{4} \cdot 2 \mathrm{H}_{2} \mathrm{O}\left(2 \theta: 28.5 \cdot 29.5^{\circ}, \mathrm{d}: 7.56 \AA\right)$ 그 리고 $\mathrm{CaCO}_{3}\left(2 \theta: 29 \sim 30^{\circ}, \mathrm{d}: 3.035 \AA\right)$ 에 대해서는 $\mathrm{XRD}$ 를 이용하여 미반응량을 정량하여 반응율을 구하였다. 내부 표준물질로서는 $\mathrm{MgO}\left(2 \theta: 42.5 \sim 43.5^{\circ}, \mathrm{d}: 2.106 \AA\right)$ 을 사용하 였으며, 각 시료에 대해서 내할로 $10 \mathrm{wt} \%$ 첨가하였다. 회절 분석의 면적을 최소이승법으로 측정피크를 fitting한 계수를 수치적분 하여 구하였다. 또한 수화물의 정량은 합성한 표 준시료를 사용하여 같은 방법으로 정량분석을 하였다. $\mathrm{C}_{3} \mathrm{~A}-$ $\mathrm{CaSO}_{4} \cdot 2 \mathrm{H}_{2} \mathrm{O}-\mathrm{CaCO}_{3}$ 계의 수화물은 ettringite(Ett, $2 \theta: 8.5 \sim 9.5^{\circ}$, $\mathrm{d}: 9.73 \AA$ ), monosulfoaluminate(Ms, $\left.2 \theta: 9.5 \sim 10.5^{\circ}, \mathrm{d}: 8.92 \AA\right)$, monocarboaluminate(Mc, $\left.2 \theta: 11 \sim 12^{\circ}, \mathrm{d}: 7.6 \AA\right)$, Hemicarboaluminate (Hc, $2 \theta: 9.8 \sim 11^{\circ}, \mathrm{d}: 8.27 \AA$ ) 이다.

\section{3. 결과 및 고찰}

\section{1. $\mathrm{C}_{3} \mathrm{~A}-\mathrm{CaSO}_{4} \cdot 2 \mathrm{H}_{2} \mathrm{O}$ 계의 수화반응에 미치는 $\mathrm{CaCO}_{3}$ 의} 영향

$\mathrm{OPC}$ 에서의 일반적인 $\mathrm{C}_{3} \mathrm{~A}$ 와 $\mathrm{CaSO}_{4} \cdot 2 \mathrm{H}_{2} \mathrm{O}$ 비율인 $\mathrm{C} 3 \mathrm{~A}-$ $2 / 3 \mathrm{CaSO}_{4} \cdot 2 \mathrm{H}_{2} \mathrm{O}$ 에 대해서 $\mathrm{CaCO}_{3}$ 첨가에 따른 영향을 알아 보기 위하여 $\mathrm{CaCO}_{3}$ 의 첨가량 및 비표면적 변화시켰을 때의 $\mathrm{XRD}$ 정량분석 결과에 따른 $\mathrm{C}_{3} \mathrm{~A}$ 의 반응율을 Fig. 1 에 나타 내었다. $\mathrm{C}_{3} \mathrm{~A}$ 의 초기수화반응은 $\mathrm{CaCO}_{3}$ 첨가에 따라 억제되 어지고 있음을 알 수 있다. 또한 $15 \%$ 첨가였을 때 보다 $30 \%$ 로 첨가량이 많을수록 억제 효과는 크게 나타났다. 그리고 석회석 미분말의 참가량이 $15 \%$ 로 동일 할 경우 비표면적이 낮은 $\left(0.75 \mathrm{~g} / \mathrm{m}^{2}\right)$ 조성보다 비표면적이 높은 $\left(1.70 \mathrm{~m}^{2} / \mathrm{g}\right)$ 조성 에서 초기의 $\mathrm{C}_{3} \mathrm{~A}$ 의 수화반응 억제 효과가 크게 나타났다. 수화반응 6시간 이후부터는 $\mathrm{C}_{3} \mathrm{~A}$ 의 반응이 급격하게 일어 나고 있으며, $\mathrm{C}_{3} \mathrm{~A}$ 의 반응율은 $\mathrm{CaCO}_{3}$ 를 첨가하지 않은 조 성보다는 $\mathrm{CaCO}_{3}$ 를 첨가한 조성에서 $\mathrm{C}_{3} \mathrm{~A}$ 의 반응율은 전체

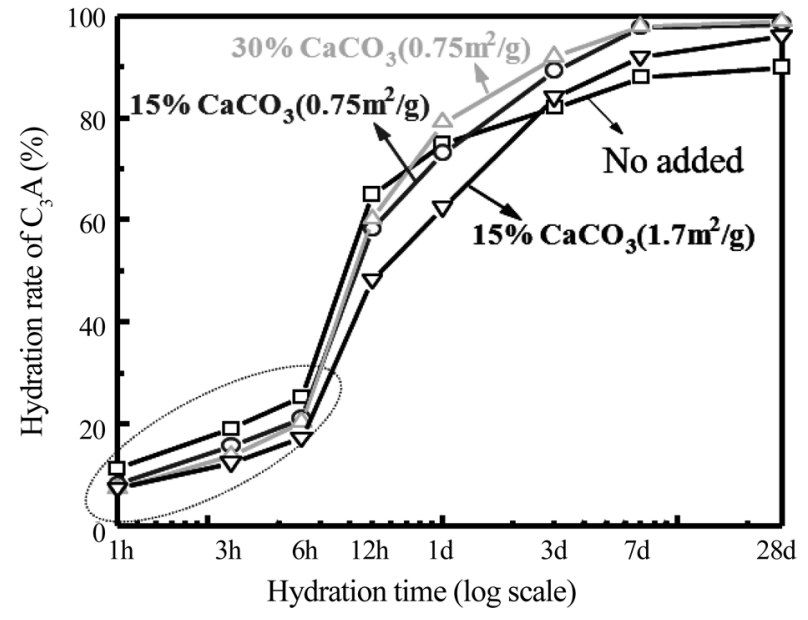

Fig. 1. Hydration rate of $\mathrm{C}_{3} \mathrm{~A}$ for $\mathrm{C}_{3} \mathrm{~A}-\mathrm{CaSO}_{4} 2 \mathrm{H}_{2} \mathrm{O}-\mathrm{CaCO}_{3}$ system.

적으로 높게 나타나고 있다.

Fig. 2에 $\mathrm{C}_{3} \mathrm{~A}-2 / 3 \mathrm{CaSO}_{4} \cdot 2 \mathrm{H}_{2} \mathrm{O}$ 의 기본조성에서 $\mathrm{CaCO}_{3}$ 첨가 에 따른 $\mathrm{CaCO}_{3}$ 와 $\mathrm{CaSO}_{4} \cdot 2 \mathrm{H}_{2} \mathrm{O}$ 의 반응율을 나타내었다. $\mathrm{CaCO}_{3}$ 는 $\mathrm{CaSO}_{4} \cdot 2 \mathrm{H}_{2} \mathrm{O}$ 가 소멸되기 전에는 거의 반응을 하고 있지 않음을 알 수 있다. 이는 우선적으로 $\mathrm{C}_{3} \mathrm{~A}$ 가 $\mathrm{CaSO}_{4}$. $2 \mathrm{H}_{2} \mathrm{O}$ 와 반응하여 Ettringite 수화물이 먼저 생기기 때문일 것 이라 생각된다. $\mathrm{C}_{3} \mathrm{~A}$ 와 $\mathrm{CaSO}_{4} \cdot 2 \mathrm{H}_{2} \mathrm{O}$ 의 반응이 완료되기 시작 하는 수화 6시간 이후부터 $\mathrm{CaCO}_{3}$ 는 급격한 반응을 보이고 있다. $\mathrm{CaSO}_{4} \cdot 2 \mathrm{H}_{2} \mathrm{O}$ 가 소비되는 시간은 $\mathrm{CaCO}_{3}$ 의 첨가량이 많을수록 또한 미세한 $\mathrm{CaCO}_{3}$ 를 첨가할수록 늦어지고 있음 을 보여주고 있다. 또한 비표면적이 $0.75 \mathrm{~m}^{2} / \mathrm{g}$ 의 $\mathrm{CaCO}_{3}$ 를 첨가한 경우 $\mathrm{CaSO}_{4} \cdot 2 \mathrm{H}_{2} \mathrm{O}$ 남아있을동안의 반응율은 미미 하지만, 미세한 $\mathrm{CaCO}_{3}$ (비표면적 $1.7 \mathrm{~m}^{2} / \mathrm{g}$ )를 첨가한 경우 초 기에 큰 반응율을 보이고 있다. 따라서 초기반응에서 미세 한 $\mathrm{CaCO}_{3}$ 를 첨가한경우 $\mathrm{SO}_{4}{ }^{2-}$ 이온뿐만 아니라 $\mathrm{CO}_{3}{ }^{2-}$ 이온

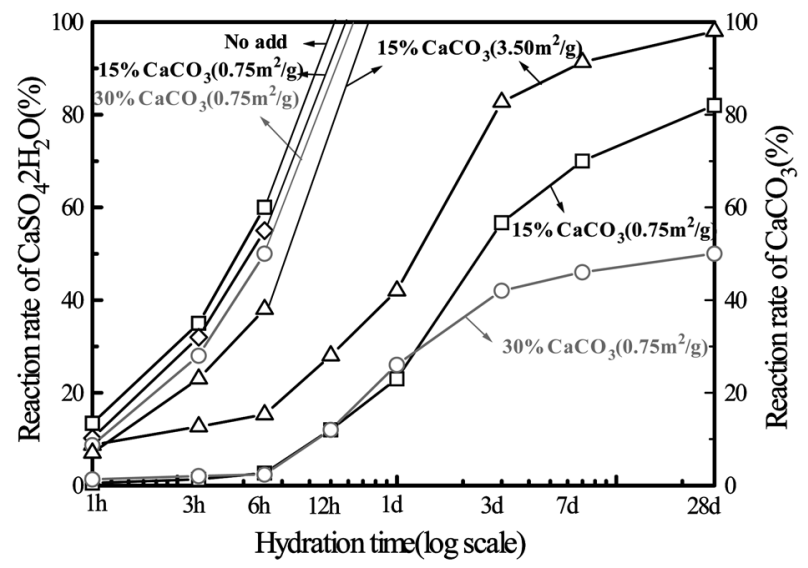

Fig. 2. Reaction rate of $\mathrm{CaSO}_{4} \cdot 2 \mathrm{H}_{2} \mathrm{O}$ and $\mathrm{CaCO}_{3}$ for $\mathrm{C}_{3} \mathrm{~A}$ $\mathrm{CaSO}_{4} \cdot 2 \mathrm{H}_{2} \mathrm{O}-\mathrm{CaCO}_{3}$ system. 
에 의해 초기수화가 억제된다고 판단하였다.

$\mathrm{C}_{3} \mathrm{~A}-\mathrm{CaSO}_{4} \cdot 2 \mathrm{H}_{2} \mathrm{O}-\mathrm{CaCO}_{3}$ 계의 수화반응을 정략적으로 알아 보기 위하여 $\mathrm{XRD}$ 정량분석에 의하여 $\mathrm{C}_{3} \mathrm{~A}, \mathrm{CaSO}_{4} \cdot 2 \mathrm{H}_{2} \mathrm{O}$ 및 $\mathrm{CaCO}_{3}$ 의 반응율과 $\mathrm{C}_{3} \mathrm{~A}-\mathrm{CaSO}_{4} \cdot 2 \mathrm{H}_{2} \mathrm{O}-\mathrm{CaCO}_{3}$ 계의 수화생성물 인 ettringite(이하 Ett로 표기), monosulfoaluminate(이하 $\mathrm{Ms}$ 로 표기), monocarboaluminate(이하 Mc로 표기), hemicarboaluminate (이하 $\mathrm{Hc}$ 로 표기)의 정량분석을 기초로 하여 수화반응에 따른 상조성을 나타내었다. 여기에서 $\mathrm{CAHx}$ 상을 포함하는 수화물을 겔상 수화물로 반응량과 생성물의 정량결과를 기초로 계산하여 구하였다.

Fig. 3에 먼저 $\mathrm{CaCO}_{3}$ 를 첨가하지 않은 $\mathrm{C}_{3} \mathrm{~A}-2 / 3 \mathrm{CaSO}_{4} \cdot 2 \mathrm{H}_{2} \mathrm{O}$ 계의 정량분석 결과로 얻은 상조성을 나타내었다. 잘 알려 진 대로 반응초기에는 겔상의 수화물과 $\mathrm{Ett}$ 가 생성하게 된 다. $\mathrm{CaSO}_{4} \cdot 2 \mathrm{H}_{2} \mathrm{O}$ 가 소비되고 난 후부터 $\mathrm{Ett}$ 는 $\mathrm{Ms}$ 전이를 하 기 시작되며, 수화 28 일에는 $\mathrm{Ett}$ 는 $\mathrm{Ms}$ 로 완전히 전이를 하고 있다.

Fig. 4에는 $\mathrm{C}_{3} \mathrm{~A}-2 / 3 \mathrm{CaSO}_{4} \cdot 2 \mathrm{H}_{2} \mathrm{O}$ 의 조성에서 비표면적

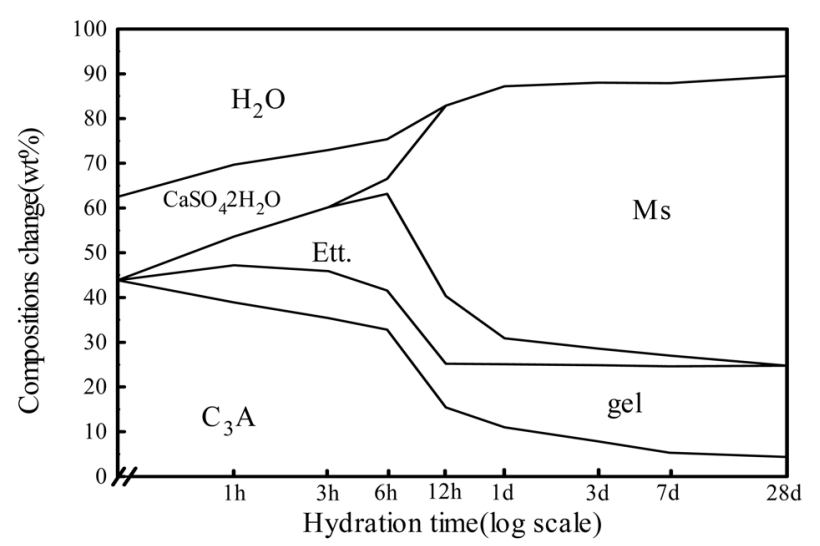

Fig. 3. Phase Composition of $\mathrm{C}_{3} \mathrm{~A}-2 / 3 \mathrm{CaSO}_{4} \cdot 2 \mathrm{H}_{2} \mathrm{O}$ system.

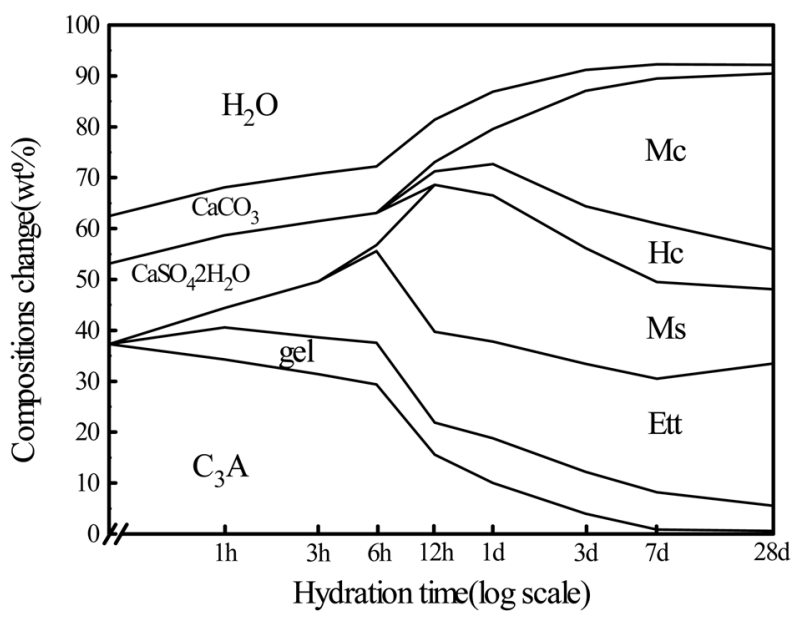

Fig. 4. Phase Composition of $\mathrm{C}_{3} \mathrm{~A}-2 / 3 \mathrm{CaSO}_{4} \cdot 2 \mathrm{H}_{2} \mathrm{O}-15 \% \mathrm{CaCO}_{3}$ $\left(0.75 \mathrm{~m}^{2} / \mathrm{g}\right)$ system.

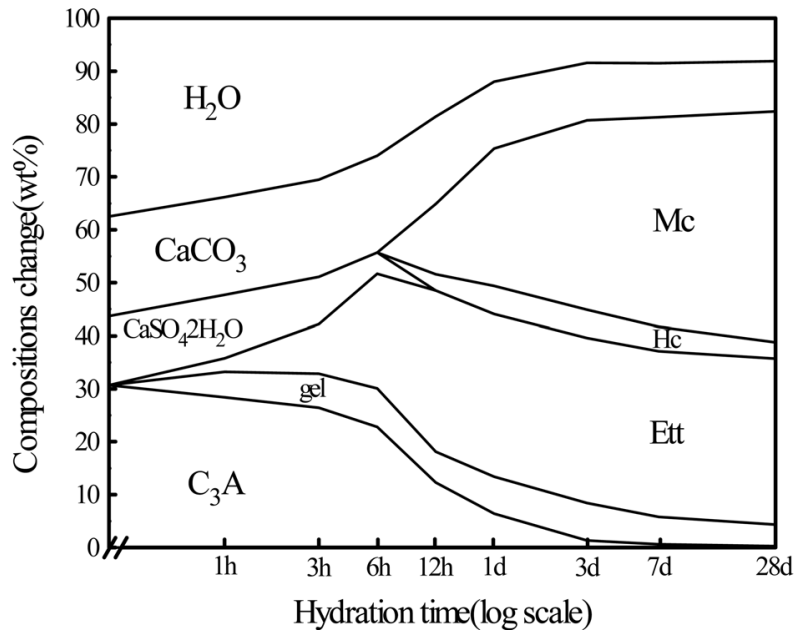

Fig. 5. Phase Composition of $\mathrm{C}_{3} \mathrm{~A}-2 / 3 \mathrm{CaSO}_{4} \cdot 2 \mathrm{H}_{2} \mathrm{O}-30 \% \mathrm{CaCO}_{3}$ $\left(0.75 \mathrm{~m}^{2} / \mathrm{g}\right)$ system.

$0.75 \mathrm{~m}^{2} / \mathrm{g}$ 의 $\mathrm{CaCO}_{3}$ 를 $15 \%$ 첨가한 경우의 상조성 결과를 나 타내었다. $\mathrm{CaCO}_{3}$ 무첨가와 마찬가지로 반응초기에는 겔상 의 수화물과 $\mathrm{Ett}$ 가 생성되고 있지만, $\mathrm{CaSO}_{4} \cdot 2 \mathrm{H}_{2} \mathrm{O}$ 가 소비되 고 난 다음부터 $\mathrm{Ms}$ 가 생성됨과 동시에 $\mathrm{CaCO}_{3}$ 의 반응도 일어나기 시작하여 $\mathrm{Mc}$ 와 $\mathrm{Hc}$ 가 생성되고 있음을 알 수 있다. $\mathrm{CaCO}_{3}$ 를 첨가하지 않은 경우에는(FIg .3) $\mathrm{Ett}$ 는 모두 $\mathrm{Ms}$ 로 전이를 하지만 $\mathrm{CaCO}_{3}$ 를 첨가한 경우에는 $\mathrm{Ett}$ 는 $\mathrm{Ms}$ 로 완전 히 전이를 하지 않는다. 이는 미반응의 $\mathrm{C}_{3} \mathrm{~A}$ 와 $\mathrm{Ett}$ 와 반응해서 $\mathrm{Ms}$ 를 생성하는 반응과 $\mathrm{C}_{3} \mathrm{~A}$ 와 $\mathrm{CaCO}_{3}$ 의 반응하여 $\mathrm{Mc}$ 및 $\mathrm{Hc}$ 가 생성되는 반응이 경쟁적으로 일어나기 때문이라고 생 각된다.

Fig. 5 에는 $\mathrm{C}_{3} \mathrm{~A}-2 / 3 \mathrm{CaSO}_{4} \cdot 2 \mathrm{H}_{2} \mathrm{O}$ 의 조성에서 비표면적 $0.75 \mathrm{~m}^{2} / \mathrm{g}$ 의 $\mathrm{CaCO}_{3}$ 를 $30 \%$ 첨가한 경우의 상조성 결과를 나 타내었다. 수화초기에는 $\mathrm{CaCO}_{3}$ 무첨가(Fig. 3) 및 $15 \%$ 첨가

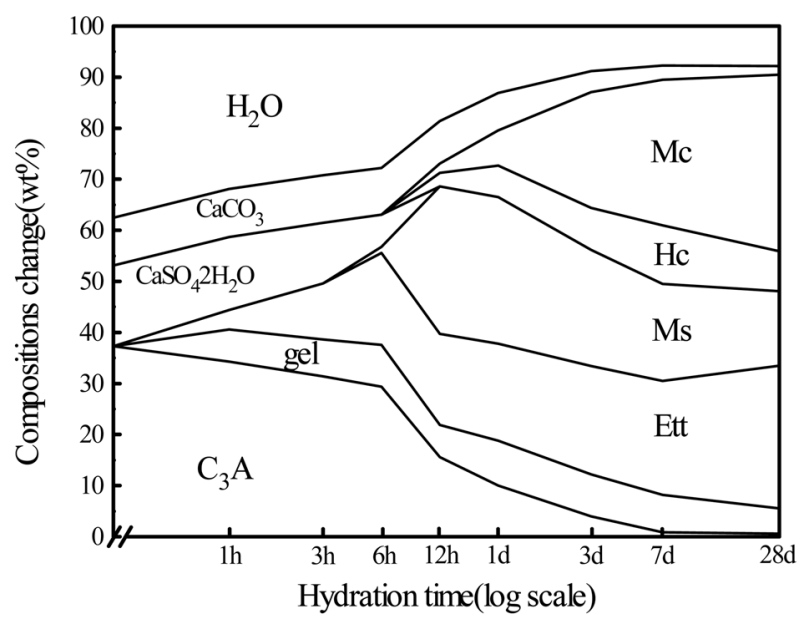

Fig. 6. Phase Composition of $\mathrm{C}_{3} \mathrm{~A}-2 / 3 \mathrm{CaSO}_{4} \cdot 2 \mathrm{H}_{2} \mathrm{O}-15 \% \mathrm{CaCO}_{3}$ $\left(1.70 \mathrm{~m}^{2} / \mathrm{g}\right)$ system. 
한 경우(Fig. 4)와 마찬가지로 겔상의 수화물과 $\mathrm{Ett}$ 수화물이 생성된다. 일반적인 경우에는 $\mathrm{Ett}$ 는 $\mathrm{CaSO}_{4} \cdot 2 \mathrm{H}_{2} \mathrm{O}$ 가 소비되고 난 다음부터 $\mathrm{Ms}$ 로 전이를 하지만, $30 \%$ 의 $\mathrm{CaCO}_{3}$ 를 첨가한 경우에는 $\mathrm{Ms}$ 로 전이를 하지 않는다. $\mathrm{Ett}$ 가 $\mathrm{Ms}$ 로 전이를 하 지 않고, 대신에 다량의 $\mathrm{Mc}$ 와 $\mathrm{Hc}$ 가 생성되고 있음을 알 수 있다. 이는 $\mathrm{CaSO}_{4} \cdot 2 \mathrm{H}_{2} \mathrm{O}$ 가 소비된 후 $\mathrm{Ett}$ 가 $\mathrm{C}_{3} \mathrm{~A}$ 와 반응하여 $\mathrm{Ms}$ 로 전이를 하는 반응보다 $\mathrm{CaCO}_{3}$ 가 다량으로 존재하기 때 문에 $\mathrm{C}_{3} \mathrm{~A}$ 와 $\mathrm{CaCO}_{3}$ 가 반응을 하여 $\mathrm{Mc}$ 및 $\mathrm{Hc}$ 를 생성하는 반응이 먼저 일어나기 때문이라고 생각된다.

Fig. 6에는 $\mathrm{C}_{3} \mathrm{~A}-2 / 3 \mathrm{CaSO}_{4} \cdot 2 \mathrm{H}_{2} \mathrm{O}$ 의 조성에서 비표면적 $1.70 \mathrm{~m}^{2} / \mathrm{g}$ 의 미세한 입도의 $\mathrm{CaCO}_{3}$ 를 $15 \%$ 첨가한 경우의 상조성 결과를 나타내었다. 수화초기에는 겔상의 수화물과 $\mathrm{Ett}$ 가 생성되고 있지만, 이 경우에도 $30 \%$ 의 $\mathrm{CaCO}_{3}$ 를 첨가 된 경우(Fig. 5)와 마친가지로 $\mathrm{Ett}$ 는 $\mathrm{Ms}$ 로 전이를 하지 않고 다량의 $\mathrm{Mc}$ 와 $\mathrm{Hc}$ 가 생성되고 있음을 알 수 있다. 이와 같이 $\mathrm{CaCO}_{3}$ 의 첨가량이 많거나 미세한 $\mathrm{CaCO}_{3}$ 를 첨가한 경우에 는 $\mathrm{CaSO}_{4} \cdot 2 \mathrm{H}_{2} \mathrm{O}$ 가 소비되고 난 후 $\mathrm{CO}_{3}{ }^{2-}$ 가 빠르게 공급되기 때문에 $\mathrm{Ett}$ 가 $\mathrm{Ms}$ 로 전이하는 반응보다 $\mathrm{Mc}$ 및 $\mathrm{Hc}$ 가 생성 하는 반응이 먼저 일어나기 때문이라 생각된다.

\section{2. $\mathrm{CaSO}_{4} \cdot 2 \mathrm{H}_{2} \mathrm{O}$ 첨가량의 영향}

일반적으로 $\mathrm{CaSO}_{4} \cdot 2 \mathrm{H}_{2} \mathrm{O}$ 의 함량에 따라 $\mathrm{C}_{3} \mathrm{~A}$ 의 초기 수 화반응은 크게 영향을 미친다. 석회석 미분말 존재하의 $\mathrm{CaSO}_{4} \cdot 2 \mathrm{H}_{2} \mathrm{O}$ 의 영향을 검토하기 위하여 $\mathrm{C}_{3} \mathrm{~A} 1$ 몰에 대해서 $1 / 3$ 몰, $2 / 3$ 몰. 1 몰의 $\mathrm{CaSO}_{4} \cdot 2 \mathrm{H}_{2} \mathrm{O}$ 조성에서 $\mathrm{CaCO}_{3}$ 를 $15 \%$ 첨가하였을 경우의 수화반응을 정량적으로 분석하였다. Fig. 6 에 $\mathrm{C}_{3} \mathrm{~A}-1 / 3 \mathrm{CaSO}_{4} \cdot 2 \mathrm{H}_{2} \mathrm{O}$ 조성에서 비표면적 $0.75 \mathrm{~m}^{2} / \mathrm{g}$ 의 $\mathrm{CaCO}_{3}$ 를 $15 \%$ 첨가한 경우의 상조성 결과를 나타내었다. 앞서 2/3몰의 $\mathrm{CaCO}_{3}$ 를 첨가한 경우(Fig. 4)에는 $\mathrm{CaSO}_{4} \cdot 2 \mathrm{H}_{2} \mathrm{O}$ 가 완전히 반응하는 시간은 12 시간 이었으나, $1 / 3$ 몰로

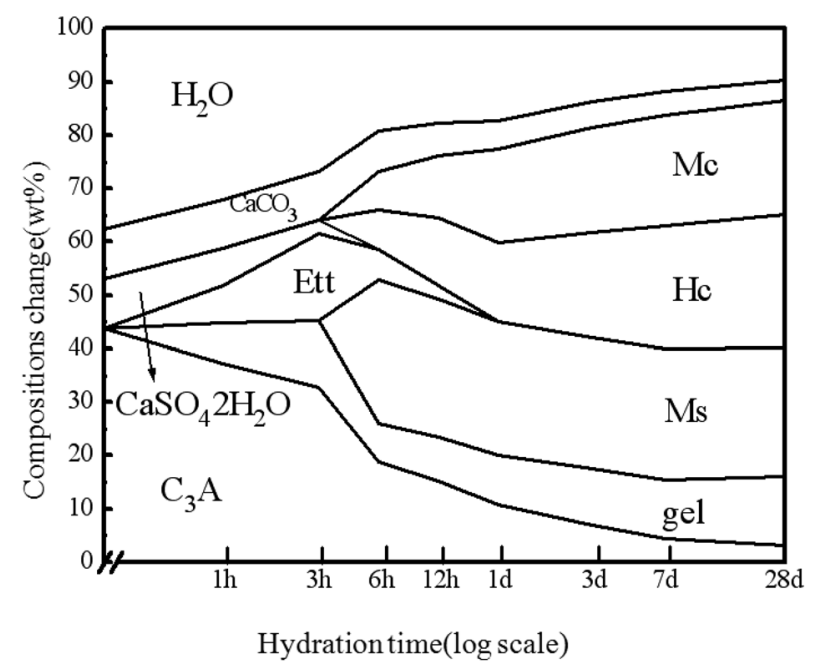

Fig. 7. Phase Composition of $\mathrm{C}_{3} \mathrm{~A}-1 / 3 \mathrm{CaSO}_{4} \cdot 2 \mathrm{H}_{2} \mathrm{O}-15 \% \mathrm{CaCO}_{3}$ $\left(0.75 \mathrm{~m}^{2} / \mathrm{g}\right)$ system.
$\mathrm{CaSO}_{4} \cdot 2 \mathrm{H}_{2} \mathrm{O}$ 의 첨가량이 적은 경우에는 수화 6시간 이후에 는 $\mathrm{CaSO}_{4} \cdot 2 \mathrm{H}_{2} \mathrm{O}$ 가 완전히 반응을 한다. $\mathrm{Ett}$ 의 경우 $2 / 3$ 몰의 $\mathrm{CaSO}_{4} \cdot 2 \mathrm{H}_{2} \mathrm{O}$ 를 첨가한 경우에는 수화 28 일까지 남아있지만, $1 / 3$ 몰로 $\mathrm{CaSO}_{4} \cdot 2 \mathrm{H}_{2} \mathrm{O}$ 의 첨가량이 적은 경우에는 $\mathrm{Ett}$ 는 수화 반응 1 일 이후에는 전부 $\mathrm{Ms}$ 로 전이를 하게 된다. $\mathrm{CaSO}_{4}$. $2 \mathrm{H}_{2} \mathrm{O}$ 가 빨리 없어지기 때문에 전체적인 반응이 빨리 수화 3 시간 이후 $\mathrm{CaCO}_{3}$ 가 반응을 시작하여 $\mathrm{Mc}$ 및 $\mathrm{Hc}$ 가 생성 되고 있음을 알 수 있다.

Fig. 7에는 $\mathrm{C}_{3} \mathrm{~A}$ 1몰에 대해서 $\mathrm{CaSO}_{4} \cdot 2 \mathrm{H}_{2} \mathrm{O}$ 1몰로 과량의 $\mathrm{CaSO}_{4} \cdot 2 \mathrm{H}_{2} \mathrm{O}$ 를 첨가한 조성에서 비표면적 $0.75 \mathrm{~m}^{2} / \mathrm{g}$ 의 $\mathrm{CaCO}_{3}$ 를 $15 \%$ 첨가한 경우의 상조성 결과를 나타내었다.

$\mathrm{CaSO}_{4} \cdot 2 \mathrm{H}_{2} \mathrm{O}$ 의 첨가량이 많기 때문에 $\mathrm{CaSO}_{4} \cdot 2 \mathrm{H}_{2} \mathrm{O}$ 가 완 전히 반응하는 시간은 수화 1 일 이후로 좀 더 길어지게 된다. $\mathrm{CaSO}_{4} \cdot 2 \mathrm{H}_{2} \mathrm{O}$ 가 소비됨과 거의 동시에 $\mathrm{Ett}$ 는 $\mathrm{Ms}$ 로 전 이를 하게 되는데 $\mathrm{Ms}$ 의 생성량을 다른 조성에 비해서는 적 게 나타났으며, $\mathrm{Ett}$ 는 전부 $\mathrm{Ms}$ 로 전이하지 않고 수화 28일 까지 일정량 그대로 유지를 하였다. $\mathrm{CaSO}_{4} \cdot 2 \mathrm{H}_{2} \mathrm{O}$ 가 소비됨 과 거의 동시에 $\mathrm{CaCO}_{3}$ 도 반응을 시작하게 되어 수화반응 1 일 이후부터 $\mathrm{Mc}, \mathrm{Hc}$ 가 생성되고 있음을 알 수 있다.

\subsection{Delayed Ettringite Formation}

일반적으로 Delayed Ettringite Formation(이하 DEF로 표 기)은 고온양생이나 $\mathrm{SO}_{4}^{2-}$ 이온의 침투에 의한 내 - 외부적 인 요인으로 경화된 후 2차적으로 다시 ettringite가 생성되는 것으로 $\mathrm{DEF}$ 가 생성되면 부피팽창에 의하여 구조체가 파괴 될 가능성이 있다. ${ }^{11,12)}$ 석회석 미분말을 첨가하였을 경우에 도 이와 유사한 $\mathrm{DEF}$ 의 가능성이 있다. 일반적으로 $\mathrm{CaCO}_{3}$ 무첨가의 경우(Fig. 3)에는 $\mathrm{Ett}$.는 $\mathrm{Ms}$ 로 완전히 전이를 하게 되고, 어떤 외부적인 요인이 없으면 다시 $\mathrm{Ett}$ 가 생성되는 $\mathrm{DEF}$ 는 발생하지 않는다. 이에 반해서 $\mathrm{CaCO}_{3}$ 를 첨가한 경우에

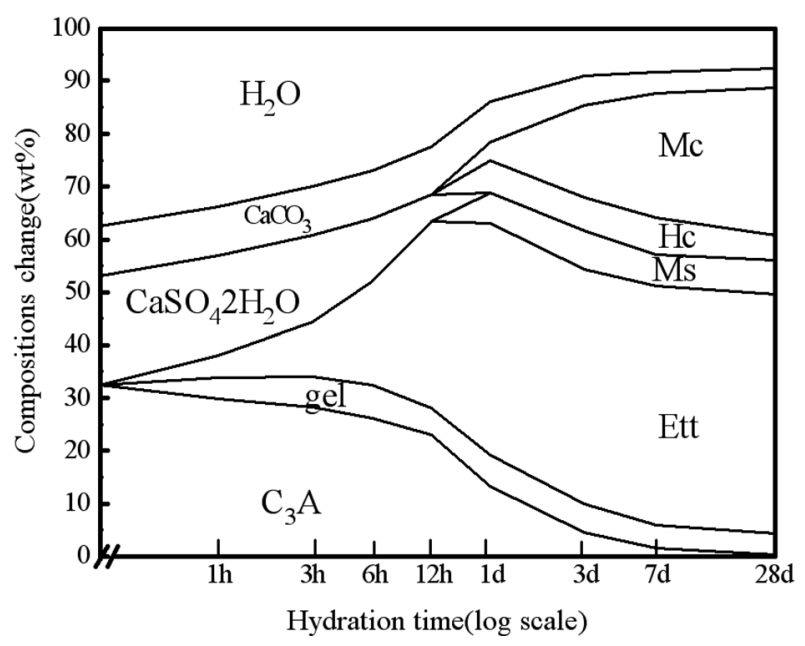

Fig. 8. Phase Composition of $\mathrm{C}_{3} \mathrm{~A}-\mathrm{CaSO}_{4} \cdot 2 \mathrm{H}_{2} \mathrm{O}-15 \% \mathrm{CaCO}_{3}$ $\left(0.75 \mathrm{~m}^{2} / \mathrm{g}\right)$ system. 
Table 1. Solubility Product of $\mathrm{CaCO}_{3}$ and $\mathrm{Ms}, \mathrm{Mc}$, Ett at $25^{\circ} \mathrm{C}$

\begin{tabular}{cc}
\hline Salts & Solubility Product at $25^{\circ} \mathrm{C}$ \\
\hline $\mathrm{CaCO}_{3}($ Calcite $)$ & $8.7 \times 10^{-7}$ \\
$\mathrm{C}_{3} \mathrm{~A} \cdot \mathrm{CaSO}_{4} \cdot 12 \mathrm{H}_{2} \mathrm{O}(\mathrm{Ms})$ & $1.7 \times 10^{-28}$ \\
$\mathrm{C}_{3} \mathrm{~A} \cdot \mathrm{CaCO}_{3} \cdot 11 \mathrm{H}_{2} \mathrm{O}(\mathrm{Mc})$ & $1.4 \times 10^{-30}$ \\
$\mathrm{C}_{3} \mathrm{~A} \cdot 3 \mathrm{CaSO}_{4} \cdot 32 \mathrm{H}_{2} \mathrm{O}(\mathrm{Ett})$ & $1.1 \times 10^{-40}$ \\
\hline
\end{tabular}

는 첨가량이나 비표면적에 따라 $\mathrm{DEF}$ 의 가능성이 존재하게 된다. Fig. 4 의 $\mathrm{C}_{3} \mathrm{~A}-2 / 3 \mathrm{CaSO}_{4} \cdot 2 \mathrm{H}_{2} \mathrm{O}$ 의 조성에서 비표면적 $0.75 \mathrm{~m}^{2} / \mathrm{g}$ 의 $\mathrm{CaCO}_{3}$ 를 $15 \%$ 첨가한 경우의 상조성 결과에서 보면, 수화 7일 이후에 $\mathrm{Ms}$ 는 줄어들고 $\mathrm{Ett}$ 가 다시 증가하는 $\mathrm{DEF}$ 가 발생함을 알 수 있다. 이는 수화 7일 이후부터는 $\mathrm{Ms}$ 가 미반응의 $\mathrm{CaCO}_{3}$ 와 반응을 하여 $\mathrm{Mc}$ 를 생성하게 되어 $\mathrm{Ms}$ 중의 $\mathrm{CaSO}_{4} \cdot 2 \mathrm{H}_{2} \mathrm{O}$ 가 빠져나와 다시 반응을 하여 $\mathrm{Ett}$ 가 증가되는 것으로 생각된다. 이는 Table 1에 나타낸 것과 같 이 각 수화물의 용해도적과 관계된 것으로 생각되며, $\mathrm{Ms}$ 보 다는 $\mathrm{Mc}, \mathrm{Mc}$ 보다는 $\mathrm{Ett}$.가 더욱 안정된 수화물이 된다. 따 라서 $\mathrm{CaCO}_{3}$ 를 첨가 하였을 경우에는 $\mathrm{Ms}$ 생성되지 않아야 $\mathrm{DEF}$ 를 막을 수 있을 것으로 생각된다. 반면에 비표면적 $0.75 \mathrm{~m}^{2} / \mathrm{g}$ 의 $\mathrm{CaCO}_{3}$ 를 $30 \%$ 로 첨가량을 늘린 경우와(Fig. 5) 비 표면적 $1.70 \mathrm{~m}^{2} / \mathrm{g}$ 의 $\mathrm{CaCO}_{3}$ 를 $15 \%$ 로 미세한 $\mathrm{CaCO}_{3}$ 를 첨 가한 경우에는(Fig. 6) DEF가 발생하지 않았다. 이는 앞서 말한 바와 같이 $\mathrm{CaCO}_{3}$ 를 첨가량을 늘린 경우와 미세한 $\mathrm{CaCO}_{3}$ 를 첨가한 경우에는 $\mathrm{Ett}$.가 $\mathrm{Ms}$ 로 전이하는 반응보다 는 $\mathrm{Mc}$ 및 $\mathrm{Hc}$ 가 먼저 생성되기 때문인 것으로 판단된다. 즉 $\mathrm{Ms}$ 자체가 생성되지 않기 때문에 DEF도 발생되지 않는다.

\section{4. 결 론}

$\mathrm{C}_{3} \mathrm{~A}-\mathrm{CaSO}_{4} \cdot 2 \mathrm{H}_{2} \mathrm{O}-\mathrm{CaCO}_{3}$ 계의 수화반응의 정량분석 검토 한 결과 다음과 같은 결론을 얻었다.

1) $\mathrm{C}_{3} \mathrm{~A}-\mathrm{CaSO}_{4} \cdot 2 \mathrm{H}_{2} \mathrm{O}-\mathrm{CaCO}_{3}$ 계에서 초기수화 반응은 $\mathrm{CaCO}_{3}$ 를 첨가함에 따라 지연 되 고 있으며 지연효과는 첨가량이 늘어날수록 미세한 $\mathrm{CaCO}_{3}$ 를 첨가할수록 증가하였다.

2) $\mathrm{CaCO}_{3}$ 는 $\mathrm{CaSO}_{4} \cdot 2 \mathrm{H}_{2} \mathrm{O}$ 가 전부 소비되고 난 다음부터 $\mathrm{C}_{3} \mathrm{~A}$ 와 급격한 반응을 일으켜 monocarboaluminate 및 hemicarboaluminate를 생성한다.

3) $\mathrm{CaCO}_{3}$ 무첨가의 경우에는 $\mathrm{Ett}$ 는 $\mathrm{Ms}$ 로 완전히 전이를 하지만 $\mathrm{CaCO}_{3}$ 를 첨가한 경우에는 $\mathrm{Ett}$ 는 $\mathrm{Ms}$ 로 완전히 전이
를 하지 않고 수화 28일 이후까지 남아있게 된다.

4) $\mathrm{C}_{3} \mathrm{~A}-2 / 3 \mathrm{CaSO}_{4} \cdot 2 \mathrm{H}_{2} \mathrm{O}$ 계에서 비표면적 $0.75 \mathrm{~m}^{2} / \mathrm{g}$ 의 $\mathrm{CaCO}_{3}$ 를 첨가한 경우 수화 7일 이후 다시 $\mathrm{Ett}$ 량이 증가하는 $\mathrm{DEF}$ 가 발생하였다.

5) $30 \%$ 의 $\mathrm{CaCO}_{3}$ 를 첨가하거나 $1.70 \mathrm{~m}^{2} / \mathrm{g}$ 의 미세한 $\mathrm{CaCO}_{3}$ 를 첨가하였을 경우에는 $\mathrm{Ms}$ 가 생성되지 않고 $\mathrm{Ett}$ 는 장시 간동안 안정하기 때문에 $\mathrm{DEF}$ 는 나타나지 않았다.

\section{REFERENCES}

1. I. Soroka and N. Stern, "Calcareous Fillers and the Compressive Strength of Portlanf Cement," Cement Concrete Res., 6 367-76 (1976).

2. I. Soroka and N. Setter, "The Effect of Fillers on Strength of Cement Mortars," Cement Concrete Res., 7 449-56 (1977).

3. W. A. Gutteridge and J. A. Daiziel, "Filler Cement: The Effect of the Secondary Component on the Hydration of Portland Cement," Cement Concrete Res., 20 778-82 (1990).

4. P. J. M. Monteiro and P. K. Mehta, "Interaction between Carbonate Rock and Cement Paste," Cement Concrete Res., 16 127-34 (1986).

5. J. Havlica and S. Sahu, "Mechanism of Ettringite and Monosulphate Formation," Cement Concrete Res., 22 671-77 (1992).

6. J. Pommersheim and J. Chang, "Kinetics of Hydration of Tricalcium Aluminate in the Presence of Gypsum," Cement Concrete Res., 18 911-22 (1988).

7. J.-K. Lee, Y.-S. Chu, and C.-W. Kwon, "The Effects of Alkali Sulfate on the Hydration of a $\mathrm{C}_{3} \mathrm{~A}-\mathrm{CaSO}_{4} \cdot 2 \mathrm{H}_{2} \mathrm{O}$ System," J. Kor. Ceram. Soc., 44 [9] 24-30 (2003).

8. J.-K. Lee and Y.-S. Chu, "A Conversion of AFM Phases by Addition of $\mathrm{CaCO}_{3} \mathrm{CaCl}_{2}$ and $\mathrm{CaSO}_{4} \cdot 2 \mathrm{H}_{2} \mathrm{O}$ (in Korean)," $J$. Kor. Ceram. Soc., 40 [1] 471-76 (2007).

9. J. K. Lee, Y. Ohba, E. Sakai, and M. Daimon, "The Synthesis of Hydrates of $3 \mathrm{CaOAl}_{2} \mathrm{O}_{3}-\mathrm{CaSO}_{4} 2 \mathrm{H}_{2} \mathrm{O}-\mathrm{CaCO}_{3}-\mathrm{Na}_{2} \mathrm{SO}_{4}-\mathrm{H}_{2} \mathrm{O}$ System," J. Inorganic Mater., 4 196-202 (1997).

10. J.-K. Lee et al, "Influence of $\mathrm{CaSO}_{4} 2 \mathrm{H}_{2} \mathrm{O}$ on the Hydration of $3 \mathrm{CaOAl}_{2} \mathrm{O}_{3}-\mathrm{CaSO}_{4} 2 \mathrm{H}_{2} \mathrm{O}-\mathrm{CaCO}_{3}$ System," J. Inorganic Mater., 5 194-98 (1998).

11. H. F. W Taylor, C. Famy, and K.L Scrivener, "Delayed Ettringite Formation," Cement Concrete Res., 31 683-93 (2001).

12. M. Collepardi, "A State of the Art Review on Delayed Ettringite Attack on Concrete," Cement Concrete Comp., 25 401-407 (2003). 